\title{
Novel Multipotent Tacrine-Dihydropyridine Hybrids with Improved Acetylcholinesterase Inhibitory and Neuroprotective Activities, as Potential Drugs for the Treatment of Alzheimer's Disease
}

\author{
José Marco-Contelles, ${ }^{\mathrm{a},}$ Rafael León, ${ }^{\text {a,b }}$ Cristóbal de los Ríos, ${ }^{\text {a,b }}$ Antonio Guglietta, ${ }^{\mathrm{c}}$ \\ José Terencio, ${ }^{\mathrm{c}}$ Manuela G. López, ${ }^{\mathrm{b}}$ Antonio G. García, ${ }^{\mathrm{b}, \mathrm{d}}$ and Mercedes Villarroya ${ }^{\mathrm{b}, *}$ \\ ${ }^{a}$ Laboratorio de Radicales Libres (IQOG, CSIC), C/ Juan de la Cierva 3, 28006-Madrid. Spain \\ ${ }^{b}$ Instituto Teófilo Hernando, Departamento de Farmacología y Terapéutica, Facultad de Medicina, \\ Universidad Autónoma de Madrid, C/ Arzobispo Morcillo 4, 28029 Madrid, Spain \\ ${ }^{c}$ Ferrer Internacional, S.A. Juan de Sada, 28-32, 08028 Barcelona, Spain \\ ${ }^{d}$ Servicio de Farmacología Clinica, Hospital Universitario de la Princesa, c/ Diego de León 62, 28006 \\ Madrid, Spain
}

\section{Supporting Information Available}

General Methods. Reactions were monitored by TLC using percolated silica gel aluminium plates containing a fluorescent indicator (Merck, 5539). Detection was done by UV $(254 \mathrm{~nm})$ followed by charring with sulfuric-acetic acid spray, $1 \%$ aqueous potassium permanganate solution or $0.5 \%$ phosphomolybdic acid in $95 \%$ EtOH. Anhydrous $\mathrm{Na}_{2} \mathrm{SO}_{4}$ was used to dry organic solutions during work-ups and the removal of solvents was carried out under vacuum with a rotary evaporator. Flash column chromatography was performed using silica gel 60 (230-400 mesh, Merck). Melting points were determined on a Kofler block and are uncorrected. IR spectra were obtained on a Perkin-Elmer Spectrum One spectrophotometer. ${ }^{1} \mathrm{H}$ NMR spectra were recorded with a Varian VXR-300S spectrometer, using tetramethylsilane as internal standard and ${ }^{13} \mathrm{C}$ NMR spectra were recorded with a Bruker WP-300-SY. All the assignments for protons and carbons were in agreement with 2D COSY, gHSQC, gHMBC, and 1D NOESY spectra. Values with $\left(^{*}\right)$ can be interchanged. Elemental analyses were conducted on a Carlo Erba EA 1108 apparatus.

2-Cyano-1-ethoxy-1-ethaniminium chloride. To a solution of malononitrile $(4.0 \mathrm{~g}, 60.60 \mathrm{mmol})$ and ethanol $(5.68 \mathrm{~mL}, 96.96 \mathrm{mmol})$ in freshly distilled diethyl ether $(100 \mathrm{~mL})$ at $0{ }^{\circ} \mathrm{C}$ was bubbled $\mathrm{HCl}(\mathrm{g})$ gently, until a white precipitate was formed. The reaction mixture was stirred for an additional time $(30 \mathrm{~min}$ ) while warming to room 
temperature. The precipitate was filtered under reduced pressure and washed with cold diethyl ether. Further purification was carried out by recrystallization from ethanol to give pure 2-cyano-1-ethoxy-1-ethaniminium chloride as a white solid. Spectroscopic and analytical data was according with the literature. ${ }^{1}$

General method for the synthesis of ethyl 6-amino-4-aryl-5-cyano-2-methyl1,4-dihydropyridine-3-carboxylates. A solution of 2-cyano-1-ethoxy-1-ethaniminium chloride (1 equiv) and ammonium acetate (10 equiv) in dry methanol ( $1 \mathrm{~mL} / \mathrm{mmol})$, was refluxed 15 min under argon. Next, the corresponding ethyl 2-acetyl-3-arylprop-2enoate ( 1 equiv) was added and the mixture was refluxed for 15-20 min. When the reaction was over (TLC analysis), the crude was cooled to $4{ }^{\circ} \mathrm{C}$ overnight, after this time a precipitated solid appears. The precipitated solid was isolated by filtration, washed with cold methanol, dried and recrystallized from methanol.

\section{Ethyl 6-amino-5-cyano-2-methyl-4-phenyl-1,4-dihydropyridine-3-}

carboxylate (12). Following the General Method for the synthesis of 1,4dihydropyridines, 2-cyano-1-ethoxy-1-ethaniminium chloride $(321.9 \mathrm{mg}, 0.91 \mathrm{mmol})$ and ammonium acetate $(541.0 \mathrm{mg}, 7.02 \mathrm{mmol})$ was refluxed in methanol $(15 \mathrm{~mL}) 15$ min. Then 21 (400 mg, 1.8 mmol) was added; after 15 min, compound 12 (410 mg, 80 $\%$ ) was obtained. Spectroscopic and analytical data was according with the literature. ${ }^{2}$

Ethyl 6-amino-5-cyano-4-(4-fluorophenyl)-2-methyl-1,4-dihydropyridine-3carboxylate (13). Following the General Method for the synthesis of 1,4dihydropyridines, 2-cyano-1-ethoxy-1-ethaniminium chloride $(820.9 \mathrm{mg}, 5.51 \mathrm{mmol})$ and ammonium acetate $(1.27 \mathrm{~g}, 16.53 \mathrm{mmol})$ was refluxed in methanol $(15 \mathrm{~mL}) 15 \mathrm{~min}$. Then 22 (1 g, $4.24 \mathrm{mmol}$ ) was added; after $15 \mathrm{~min}$, compound 13 (987 mg, 78\%) was obtained: $\mathrm{mp} 223-225^{\circ} \mathrm{C}$; IR (KBr) v 3420, 3354, 3231, 2982, 2869, 2181, 1666, 1496, $1369 \mathrm{~cm}^{-1}$; ${ }^{1} \mathrm{H}$ NMR (DMSO-d 6 , $\left.300 \mathrm{MHz}\right) \delta 8.67$ (s, $\left.1 \mathrm{H}, \mathrm{NH}\right), 7.15-7.04$ (m, 4 H, H2', H3), 5.68 (s, $2 \mathrm{H}, \mathrm{NH}_{2}$ ), 4.34 (s, $\left.1 \mathrm{H}, \mathrm{H} 4\right), 3.91$ (q, J= 7.1 Hz, $2 \mathrm{H}, \mathrm{OCH}_{2} \mathrm{CH}_{3}$ ), 2.24 [s,

$3 \mathrm{H}, \mathrm{CH}_{3}(\mathrm{C} 2)$ ], $1.04\left(\mathrm{t}, J=7.1 \mathrm{~Hz}, 3 \mathrm{H}, \mathrm{CH}_{3} \mathrm{CH}_{2} \mathrm{O}\right) ;{ }^{13} \mathrm{C}$ NMR (DMSO-d 6 , $\left.75 \mathrm{MHz}\right) \delta$ 166,4 (C=O), 162.3/159.1 $\left(J_{C 4^{\prime}-F}=240.0 \mathrm{~Hz}, \mathrm{C}^{\prime}\right), 150.3$ (C6), 145.1 (C2), $143.96 / 143.93\left(\mathrm{C}, J_{C 1^{\prime}-F}=2.85 \mathrm{~Hz}, \mathrm{C}^{\prime}\right), 128.5 / 128.4\left(2 \times \mathrm{CH}, J_{C 2^{\prime} ; 6^{\prime}-F}=8.02 \mathrm{~Hz}, 2 \mathrm{x}\right.$ C2) $121.5(\mathrm{C} \equiv \mathrm{N}), 114.9 / 114,6\left(2 \times \mathrm{CH}, J_{C^{3}, 5^{\prime}-F}=21.0 \mathrm{~Hz}, 2 \times \mathrm{C}^{\prime}\right), 100.7$ (C3), 59.0 $\left(\mathrm{OCH}_{2} \mathrm{CH}_{3}\right), 57.4(\mathrm{C} 5), 39.7(\mathrm{C} 4), 18.6\left[\mathrm{CH}_{3}(\mathrm{C} 2)\right], 13.9\left(\mathrm{CH}_{3} \mathrm{CH}_{2} \mathrm{O}\right)$; MS (API-ES+) 
$m / z:[\mathrm{M}+1]^{+}$302.1; $[\mathrm{M}+\mathrm{Na}]^{+}$324.0; $[2 \mathrm{M}+1]^{+}$603.3; $[2 \mathrm{M}+\mathrm{Na}]^{+}$625.3. Anal. Calcd. for $\mathrm{C}_{16} \mathrm{H}_{16} \mathrm{~N}_{3} \mathrm{O}_{2} \mathrm{~F}: \mathrm{C}, 63.78 ; \mathrm{H}, 5.35 ; \mathrm{N}, 13.95$. Found: $\mathrm{C}, 63.31 ; \mathrm{H}, 5.27 ; \mathrm{N}, 13.60$.

\section{Ethyl 6-amino-5-cyano-2-methyl-4-(2-nitrophenyl)-1,4-dihydropyridine-3-} carboxylate (14). Following the General Method for the synthesis of 1,4dihydropyridines, 2-cyano-1-ethoxy-1-ethaniminium chloride (747.63 mg, $5.06 \mathrm{mmol}$ ) and ammonium acetate $(1.2 \mathrm{~g}, 16.30 \mathrm{mmol})$ was refluxed in methanol $(15 \mathrm{~mL}) 15 \mathrm{~min}$. Then 23 (1.1 g, $4.18 \mathrm{mmol}$ ) was added; after $25 \mathrm{~min}$, compound 14 (511 mg, 38\%) was obtained: $\mathrm{mp} 123-125^{\circ} \mathrm{C}$; IR $(\mathrm{KBr}) \vee$ 3382, 3210, 2978, 2218, 1715, 1609, 1557, 1348 $\mathrm{cm}^{-1} ;{ }^{1} \mathrm{H}$ NMR $\left(\mathrm{DMSO}_{6}, 300 \mathrm{MHz}\right) \delta 8.76(\mathrm{~s}, 1 \mathrm{H}, \mathrm{NH}), 7.77\left(\mathrm{~d}, J_{3^{\prime}-4}=7.8 \mathrm{~Hz}, 1 \mathrm{H}\right.$, $\mathrm{H} 3$ ), 7.65 (t, $\left.J_{4^{\prime}-3}=7.8 \mathrm{~Hz}, 1 \mathrm{H}, \mathrm{H} 4^{\prime}\right), 7.45\left(\mathrm{~d}, J_{6^{\prime}-5}=7.7 \mathrm{~Hz}, 1 \mathrm{H}, \mathrm{H} 6^{\prime}\right), 7.38$ (t, $J_{5^{\prime}-6^{\prime}}=$ $7.7 \mathrm{~Hz}, 1 \mathrm{H}, \mathrm{H} 5$ '), 5.76 (br s, $2 \mathrm{H}, \mathrm{NH}_{2}$ ), 5.07 (s, $\left.1 \mathrm{H}, \mathrm{H} 4\right), 3.80$ (q, J= $7.1 \mathrm{~Hz}, 2 \mathrm{H}$, $\left.\mathrm{OCH}_{2} \mathrm{CH}_{3}\right), 2.25\left[\mathrm{~s}, 3 \mathrm{H}, \mathrm{CH}_{3}(\mathrm{C} 2)\right], 0.91\left(\mathrm{t}, J=7.1 \mathrm{~Hz}, 3 \mathrm{H}, \mathrm{CH}_{3} \mathrm{CH}_{2} \mathrm{O}\right) ;{ }^{13} \mathrm{C} \mathrm{NMR}$ $\left(\mathrm{DMSO}_{-} \mathrm{d}_{6}, 75 \mathrm{MHz}\right) \delta 166.2(\mathrm{C}=\mathrm{O}), 151.2$ (C2), 147.8 (C6), 146.8 (C2), 143.1 (C1), 133.9 (C3), 130.9 (C4), 127.7 (C6'), $123.5\left(\mathrm{C}^{\prime}\right), 121.0(\mathrm{C} \equiv \mathrm{N}), 100.8(\mathrm{C} 3), 59.4$ $\left(\mathrm{OCH}_{2} \mathrm{CH}_{3}\right), 57.0$ (C5), $34.5(\mathrm{C} 4), 19.1\left[\mathrm{CH}_{3}(\mathrm{C} 2)\right], 14.1\left(\mathrm{CH}_{3} \mathrm{CH}_{2} \mathrm{O}\right)$; MS (API-ES+) $m / z:[\mathrm{M}+1]^{+}$329.1; $[\mathrm{M}+\mathrm{Na}]^{+}$351.1; $[2 \mathrm{M}+1]^{+}$657.3; [2M+Na $]^{+}$679.2. Anal. Calcd. for $\mathrm{C}_{16} \mathrm{H}_{16} \mathrm{~N}_{4} \mathrm{O}_{4}$ : C, 58.53; H, 4.91; N, 17.06. Found: C, 58.76; H, 4.91; N, 17.12.

\section{Ethyl 6-amino-5-cyano-2-methyl-4-(3-nitrophenyl)-1,4-dihydropyridine-3-}

carboxylate (15). Following the General Method for the synthesis of 1,4dihydropyridines, 2-cyano-1-ethoxy-1-ethaniminium chloride $(679.6 \mathrm{mg}, 3.57 \mathrm{mmol})$ and ammonium acetate $(1.14 \mathrm{~g}, 12.48 \mathrm{mmol})$ was refluxed in methanol $(15 \mathrm{~mL}) 15 \mathrm{~min}$. Then 24 ( $1 \mathrm{~g}, 3.2 \mathrm{mmol}$ ) was added; after $20 \mathrm{~min}$, compound 15 (950 mg, 90\%) was obtained: $\mathrm{mp} 218-220^{\circ} \mathrm{C}$; IR $(\mathrm{KBr}) \vee 3402,3362,3230,2184,1658,1530,1486,1348$ $\mathrm{cm}^{-1} ;{ }^{1} \mathrm{H}$ NMR (DMSO-d 6 , $\left.300 \mathrm{MHz}\right) \delta 8.74$ (s, $\left.1 \mathrm{H}, \mathrm{NH}\right), 8.07$ (m, $1 \mathrm{H}, \mathrm{H} 4$ ) $) 7.95$ (s, 1 H, H2), 7.62 (m, 2 H, H6', H5), 5.84 (br s, 2 H, NH 2 ), 4.54 (s, 1 H, H4), 2.10 (q, J= $\left.7.1 \mathrm{~Hz}, 2 \mathrm{H}, \mathrm{OCH}_{2} \mathrm{CH}_{3}\right), 2.29$ [s, $\left.3 \mathrm{H}, \mathrm{CH}_{3}(\mathrm{C} 2)\right], 1.06$ (t, J= 7.1 Hz, $3 \mathrm{H}, \mathrm{CH}_{3} \mathrm{CH}_{2} \mathrm{O}$ ); ${ }^{13} \mathrm{C}$ NMR (DMSO-d $\left.6,75 \mathrm{MHz}\right) \delta 166.5$ (C=O), 150.9 (C6), 150.3 (C3), 148.1 (C1), $146.5(\mathrm{C} 2), 134.0\left(\mathrm{C}^{* *}\right), 130.2\left(\mathrm{C}^{* *}\right), 121.7\left(\mathrm{C}^{* *}\right), 121.6\left(\mathrm{C} 2^{* *}\right), 121.4(\mathrm{C} \equiv \mathrm{N}), 100.3$ (C3), $59.6\left(\mathrm{OCH}_{2} \mathrm{CH}_{3}\right), 57.0$ (C5), $39.8(\mathrm{C} 4), 19.1\left[\mathrm{CH}_{3}(\mathrm{C} 2)\right], 14.2\left(\mathrm{CH}_{3} \mathrm{CH}_{2} \mathrm{O}\right)$; MS (API-ES+) $m / z:[\mathrm{M}+1]^{+} 329.1 ;[\mathrm{M}+\mathrm{Na}]^{+} 351.1 ;[2 \mathrm{M}+1]^{+}$657.3; $[2 \mathrm{M}+\mathrm{Na}]^{+}$679.2. Anal. Calcd. for $\mathrm{C}_{16} \mathrm{H}_{16} \mathrm{~N}_{4} \mathrm{O}_{4}$ : C, 58.53; H, 4.91; N, 17.06. Found: C, 58.65; H, 4.89; N, 17.22. 


\section{Ethyl 6-amino-5-cyano-2-methyl-4-(4-nitrophenyl)-1,4-dihydropyridine-3-}

carboxylate (16). Following the General Method for the synthesis of 1,4dihydropyridines, 2-cyano-1-ethoxy-1-ethaniminium chloride (747.6 mg, $5.06 \mathrm{mmol}$ ) and ammonium acetate $(1.25 \mathrm{~g}, 16.30 \mathrm{mmol})$ was refluxed in methanol $(15 \mathrm{~mL}) 15 \mathrm{~min}$. Then 25 (1.1 g, $4.18 \mathrm{mmol}$ ) was added; after $20 \mathrm{~min}$, compound 16 (796 mg, 67\%) was obtained: $\mathrm{mp} 240-242{ }^{\circ} \mathrm{C}$; IR (KBr) v 3407, 3346, 3230, 2898, 2177, 1665, 1605, 1518 , 1494, $1348 \mathrm{~cm}^{-1} ;{ }^{1} \mathrm{H}$ NMR (DMSO-d $\left.6,300 \mathrm{MHz}\right) \delta 8.79$ (s, $\left.1 \mathrm{H}, \mathrm{NH}\right), 8.18(\mathrm{~d}, J=8.2$ $\mathrm{Hz}, 2 \mathrm{H}, 2$ x H3), 7.39 (d, J= 8.2 Hz, $2 \mathrm{H}, 2$ x H2) 5.83 (s, $2 \mathrm{H}, \mathrm{NH}_{2}$ ), 4.51 (s, $1 \mathrm{H}$, H4), 3.92 (q, $\left.J=6.9 \mathrm{~Hz}, 2 \mathrm{H}, \mathrm{OCH}_{2} \mathrm{CH}_{3}\right), 2.29$ [s, $\left.3 \mathrm{H}, \mathrm{CH}_{3}(\mathrm{C} 2)\right], 1.04$ (t, $J=6.9 \mathrm{~Hz}, 3$ $\mathrm{H}, \mathrm{CH}_{3} \mathrm{CH}_{2} \mathrm{O}$ ); ${ }^{13} \mathrm{C}$ NMR (DMSO-d 6 , $\left.75 \mathrm{MHz}\right) \delta 166.5(\mathrm{C}=\mathrm{O}), 155.4\left(\mathrm{C}^{\prime}\right), 150.8(\mathrm{C} 6)$, $146.6(\mathrm{C} 2), 146.3(\mathrm{C} 1$ ), 128.2 (2 x C2) $124.0(2 \times \mathrm{C} 3$ ) $, 121.5(\mathrm{C} \equiv \mathrm{N}), 99.9(\mathrm{C} 3), 59.5$ $\left(\mathrm{OCH}_{2} \mathrm{CH}_{3}\right), 56.7$ (C5), $40.7(\mathrm{C} 4), 19.1\left[\mathrm{CH}_{3}(\mathrm{C} 2)\right], 14.3\left(\mathrm{CH}_{3} \mathrm{CH}_{2} \mathrm{O}\right)$; MS (API-ES+) $m / z:[\mathrm{M}+1]^{+}$329.0; $[\mathrm{M}+\mathrm{Na}]^{+}$351.0; $[2 \mathrm{M}+1]^{+}$657.3; [2M+Na $]^{+}$679.2. Anal. Calcd. for $\mathrm{C}_{16} \mathrm{H}_{16} \mathrm{~N}_{4} \mathrm{O}_{4}$ : C, 58.53; H, 4.91; N, 17.06. Found: C, 58.35; H, 4.87; N, 16.86.

Ethyl 6-amino-5-cyano-2-methyl-4-(4-methylphenyl)-1,4-dihydropyridine-3carboxylate (17). Following the General Method for the synthesis of 1,4dihydropyridines, 2-cyano-1-ethoxy-1-ethaniminium chloride (769.79 mg, $5.16 \mathrm{mmol}$ ) and ammonium acetate $(1.29 \mathrm{~g}, 16.77 \mathrm{mmol})$ was refluxed in methanol $(15 \mathrm{~mL}) 15 \mathrm{~min}$. Then 26 ( $1 \mathrm{~g}, 4.3 \mathrm{mmol}$ ) was added; after $20 \mathrm{~min}$, compound 17 (822.0 mg, 65\%) was obtained: $\mathrm{mp} 220-222^{\circ} \mathrm{C}$; IR (KBr) v 3407, 3347, 3227, 2181, 1664, 1405, $1321 \mathrm{~cm}^{-1}$; ${ }^{1} \mathrm{H}$ NMR (DMSO-d 6 , 300 MHz) $\delta 9.03$ (s, 1 H, NH), 7.05-6.97 (m, 4 H, 2H2', 2H3'), 5.77 (br s, $2 \mathrm{H}, \mathrm{NH}_{2}$ ), 4.28 (s, $\left.1 \mathrm{H}, \mathrm{H} 4\right), 3.91$ (q, J= 7.1 Hz, $2 \mathrm{H}, \mathrm{OCH}_{2} \mathrm{CH}_{3}$ ), 2.22 [s, 3 $\mathrm{H}, \mathrm{CH}_{3}\left(\mathrm{C}^{2}\right)$ ], $2.21\left[\mathrm{~s}, 3 \mathrm{H}, \mathrm{CH}_{3}(\mathrm{C} 2)\right], 1.06\left(\mathrm{t}, J=7.1 \mathrm{~Hz}, 3 \mathrm{H}, \mathrm{CH}_{3} \mathrm{CH}_{2} \mathrm{O}\right) ;{ }^{13} \mathrm{C} \mathrm{NMR}$ $\left(\mathrm{DMSO}_{6}, 75 \mathrm{MHz}\right) \delta 166.5(\mathrm{C}=\mathrm{O}), 150.5$ (C6), 144.8 (C2), 144.8 (C4'), 135.0 (C1)), 129.1 ( 2 x C2) $126.6\left(2 \times \mathrm{C}^{\prime}\right), 121.8(\mathrm{C} \equiv \mathrm{N}), 100.7$ (C3), $58.9\left(\mathrm{OCH}_{2} \mathrm{CH}_{3}\right), 57.3$ (C5), 39.7 (C4), $20.6\left[\mathrm{CH}_{3}(\mathrm{C} 4)\right], 18.6\left[\mathrm{CH}_{3}(\mathrm{C} 2)\right], 14.0\left(\mathrm{CH}_{3} \mathrm{CH}_{2} \mathrm{O}\right)$; MS (API-ES+) $m / z$ : $[\mathrm{M}+1]^{+}$298.1; $[\mathrm{M}+\mathrm{Na}]^{+} 320.1 ;[2 \mathrm{M}+1]^{+}$595.2; $[2 \mathrm{M}+\mathrm{Na}]^{+}$617.3. Anal. Calcd. for $\mathrm{C}_{17} \mathrm{H}_{19} \mathrm{~N}_{3} \mathrm{O}_{2}$ : C, 68.67; H, 6.44, N, 14.13. Found: C, 68.59; H, 6.33; N, 14.32.

\section{Ethyl 6-amino-5-cyano-2-methyl-4-(2-methoxyphenyl)-1,4-dihydropyridine-}

3-carboxylate (18). Following the General Method for the synthesis of 1,4dihydropyridines, 2-cyano-1-ethoxy-1-ethaniminium chloride $(720.18 \mathrm{mg}, 4.83 \mathrm{mmol})$ 
and ammonium acetate $(1.20 \mathrm{~g}, 15.67 \mathrm{mmol})$ was refluxed in methanol $(15 \mathrm{~mL}) 15 \mathrm{~min}$. Then 27 (1 g, $4.02 \mathrm{mmol}$ ) was added; after $20 \mathrm{~min}$, compound 18 (395.0 mg, 32\%) was obtained: Mp 209-211 ${ }^{\circ} \mathrm{C}$; IR (KBr) v 3370, 2971, 2833, 2180, 1629, $1367 \mathrm{~cm}^{-1}$; ${ }^{1} \mathrm{H}$ NMR (DMSO-d 6 , 300 MHz) $\delta 8.57$ (s, 1 H, NH), 7.12 (m, 1 H, H3 ), 6.90 (m, 3 H, H4', H5', H6), 5.49 (br s, 2 H, NH 2 ), 4.86 (s, $1 \mathrm{H}, \mathrm{H} 4$ ), 3.86 (q, J= 7,1 Hz, $2 \mathrm{H}, \mathrm{OCH}_{2} \mathrm{CH}_{3}$ ), $3.76\left[\mathrm{~s}, 3 \mathrm{H}, \mathrm{CH}_{3}(\mathrm{O})\right], 2.28\left[\mathrm{~s}, 3 \mathrm{H}, \mathrm{CH}_{3}(\mathrm{C} 2)\right], 0.98\left(\mathrm{t}, J=7.1 \mathrm{~Hz}, 3 \mathrm{H}, \mathrm{CH}_{3} \mathrm{CH}_{2} \mathrm{O}\right) .{ }^{13} \mathrm{C}$ NMR (DMSO-d 6 , 75 MHz) $\delta 167.1(\mathrm{C}=\mathrm{O}), 156.3(\mathrm{C} 2 *$ ), 151.0 (C6), 146.0 (C2), 136.3 (C1), $128.3\left(\mathrm{C}^{\prime *}\right), 127.6\left(\mathrm{C}^{* *}\right), 122.1(\mathrm{C} \equiv \mathrm{N}), 120.9\left(\mathrm{C}^{* *}\right), 111.4\left(\mathrm{C6}^{* *}\right), 100.7(\mathrm{C} 3)$, $59.3\left(\mathrm{OCH}_{2} \mathrm{CH}_{3}\right), 57.9(\mathrm{C} 5), 55.9 \quad\left[\mathrm{CH}_{3}(\mathrm{O})\right], 32.9(\mathrm{C} 4), 19.0 \quad\left[\mathrm{CH}_{3}(\mathrm{C} 2)\right], 14.3$ $\left(\mathrm{CH}_{3} \mathrm{CH}_{2} \mathrm{O}\right)$; MS (API-ES+) $\mathrm{m} / \mathrm{z}:[\mathrm{M}+1]^{+}$314.3; [M+Na $]^{+} 336.2 ;[2 \mathrm{M}+1]^{+}$627.5; $[2 \mathrm{M}+\mathrm{Na}]^{+}$649.5. Anal. Calcd. for $\mathrm{C}_{17} \mathrm{H}_{19} \mathrm{~N}_{3} \mathrm{O}_{3}$ : C, 65.16; H, 6.11; $\mathrm{N}, 13.41$. Found: $\mathrm{C}$, $64.93 ; \mathrm{H}, 6.40 ; \mathrm{N}, 13.61$.

\section{Ethyl 6-amino-5-cyano-2-methyl-4-(3-methoxyphenyl)-1,4-dihydropyridine-}

3-carboxylate (19). Following the General Method for the synthesis of 1,4dihydropyridines, 2-cyano-1-ethoxy-1-ethaniminium chloride (780.8 mg, $5.23 \mathrm{mmol}$ ) and ammonium acetate $(1.21 \mathrm{~g}, 15.71 \mathrm{mmol})$ was refluxed in methanol (15 mL) $15 \mathrm{~min}$. Then 28 ( $1 \mathrm{~g}, 4.21 \mathrm{mmol})$ was added; after $20 \mathrm{~min}$, compound 19 (856 mg, 65\%) was obtained: mp 192-194 ${ }^{\circ} \mathrm{C}$; IR (KBr) v 3401, 3340, 3224, 2992, 2833, 2182, 1657, 1624, 1489, $1367 \mathrm{~cm}^{-1} ;{ }^{1} \mathrm{H}$ NMR (DMSO-d $\left.6,300 \mathrm{MHz}\right) \delta 8.63$ (s, $\left.1 \mathrm{H}, \mathrm{NH}\right), 7.19(\mathrm{t}, J=7,9$ Hz, 1 H, H5 ), 6.73 (d, J= 7.9 Hz, 2 H, H4', H6'), 6.64 (br s, 1 H, H2) ), 5.68 (br s, 2 H, $\mathrm{NH}_{2}$ ), 4.33 (s, $\left.1 \mathrm{H}, \mathrm{H} 4\right), 3.94$ (q, J= $7.0 \mathrm{~Hz}, 2 \mathrm{H}, \mathrm{OCH}_{2} \mathrm{CH}_{3}$ ), 3.71 [s, $3 \mathrm{H}, \mathrm{CH}_{3}(\mathrm{O})$, $2.26\left[\mathrm{~s}, 3 \mathrm{H}, \mathrm{CH}_{3}(\mathrm{C} 2)\right], 1.08\left(\mathrm{t}, J=7.0 \mathrm{~Hz}, 3 \mathrm{H}, \mathrm{CH}_{3} \mathrm{CH}_{2} \mathrm{O}\right) ;{ }^{13} \mathrm{C} \mathrm{NMR}\left(\mathrm{DMSO}_{6}, 75\right.$ MHz) $\delta 166.5$ (C=O), 159.1 (C3), 150.4 (C6), 149.2 (C2), 145.0 (C1'), 129.2 (C5'), $121.7(\mathrm{C} \equiv \mathrm{N}), 119.0\left(\mathrm{C}^{\prime}\right), 112.9\left(\mathrm{C}^{\prime}\right), 110.8\left(\mathrm{C}^{\prime}\right), 100.7(\mathrm{C} 3), 59.0\left(\mathrm{OCH}_{2} \mathrm{CH}_{3}\right), 57.3$ (C5), $54.8\left[\mathrm{CH}_{3}(\mathrm{O})\right], 40.0(\mathrm{C} 4), 18.6\left[\mathrm{CH}_{3}(\mathrm{C} 2)\right], 14.0\left(\mathrm{CH}_{3} \mathrm{CH}_{2} \mathrm{O}\right)$; MS (API-ES+) $m / z$ : $[\mathrm{M}+1]^{+}$314.3; $[\mathrm{M}+\mathrm{Na}]^{+}$336.2; $[2 \mathrm{M}+1]^{+}$627.5; $[2 \mathrm{M}+\mathrm{Na}]^{+}$649.5. Anal. Calcd. for $\mathrm{C}_{17} \mathrm{H}_{19} \mathrm{~N}_{3} \mathrm{O}_{3}$ : C, 65.16; H, 6.11; N, 13.41. Found: C, 65.36; H, 6.25; N, 13.70.

\section{Ethyl 6-amino-5-cyano-2-methyl-4-(4-methoxyphenyl)-1,4-dihydropyridine-}

3-carboxylate (20). Following the General Method for the synthesis of 1,4dihydropyridines, 2-cyano-1-ethoxy-1-ethaniminium chloride (780.8 mg, $5.23 \mathrm{mmol}$ ) and ammonium acetate $(1.21 \mathrm{~g}, 15.71 \mathrm{mmol})$ was refluxed in methanol $(15 \mathrm{~mL}) 15 \mathrm{~min}$. 
Then 29 ( $1 \mathrm{~g}, 4.21 \mathrm{mmol}$ ) was added; after $15 \mathrm{~min}$, compound 20 (987 mg, 74\%) was obtained: $\mathrm{mp} 188-190{ }^{\circ} \mathrm{C}$; IR (KBr) v 3403, 3346, 3227, 2980, 2927, 2898, 2833, 2179 , 1662, 1496, $1320 \mathrm{~cm}^{-1} ;{ }^{1} \mathrm{H}$ NMR (DMSO-d $\left.6,300 \mathrm{MHz}\right) \delta 8.68(\mathrm{~s}, 1 \mathrm{H}, \mathrm{NH}), 7.04$ (d, J= $8.6 \mathrm{~Hz}, 2 \mathrm{H}, 2$ x H2'), 6.82 (d, J= 8.6 Hz, 2 H, 2 x H3), 5.66 (br s, 2 H, NH N $^{2}, 4.30$ (s, 1 $\mathrm{H}, \mathrm{H} 4), 3.93\left(\mathrm{q}, J=7.0 \mathrm{~Hz}, 2 \mathrm{H}, \mathrm{OCH}_{2} \mathrm{CH}_{3}\right), 3.70\left[\mathrm{~s}, 3 \mathrm{H}, \mathrm{CH}_{3}(\mathrm{O})\right], 2.24[\mathrm{~s}, 3 \mathrm{H}$, $\left.\mathrm{CH}_{3}(\mathrm{C} 2)\right], 1.08\left(\mathrm{t}, J=7.0 \mathrm{~Hz}, 3 \mathrm{H}, \mathrm{CH}_{3} \mathrm{CH}_{2} \mathrm{O}\right.$ ); ${ }^{13} \mathrm{C}$ NMR (DMSO-d 6 , $\left.75 \mathrm{MHz}\right) \delta 166.6$ $(\mathrm{C}=\mathrm{O}), 157.7$ (C4), $150.4(\mathrm{C} 6), 144.5(\mathrm{C} 2), 139.1(\mathrm{C} 1$ ), 127.7 (2 x C2) $121.8(\mathrm{C} \equiv \mathrm{N})$, 113.5 (2 x C3), $101.2(\mathrm{C} 3), 59.0\left(\mathrm{OCH}_{2} \mathrm{CH}_{3}\right), 57.7(\mathrm{C} 5), 54.9\left[\mathrm{CH}_{3}(\mathrm{O})\right], 39.5(\mathrm{C} 4)$, $18.6\left[\mathrm{CH}_{3}(\mathrm{C} 2)\right], 14.0\left(\mathrm{CH}_{3} \mathrm{CH}_{2} \mathrm{O}\right)$; MS (API-ES+) $m / z:[\mathrm{M}+1]^{+} 314.3$; $[\mathrm{M}+\mathrm{Na}]^{+} 336.2$; $[2 \mathrm{M}+1]^{+}$627.5; [2M+Na $]^{+}$649.5. Anal. Calcd. for $\mathrm{C}_{17} \mathrm{H}_{19} \mathrm{~N}_{3} \mathrm{O}_{3}: \mathrm{C}, 65.16 ; \mathrm{H}, 6.11 ; \mathrm{N}$, 13.41. Found: C, 64.89; H, 5.97; N, 13.09.

General method for the Friedländer reaction. Aluminum chloride (1.2-1.7 equiv) was suspended in dry 1,2-dichloroethane $(10 \mathrm{~mL})$ at $\mathrm{rt}$ under argon. The corresponding ethyl 6-amino-4-aryl-5-cyano-2-methyl-1,4-dihidropyridine-3carboxilate (1 equiv) and cyclohexanone (1.2-1.7 equiv) were added. The reaction mixture was heated under reflux (10-24 h). When the reaction was over (TLC analysis), a mixture of $\mathrm{THF} / \mathrm{H}_{2} \mathrm{O}(1: 1)$ was added at $\mathrm{rt}$. An aqueous solution of sodium hydroxide $(10 \%)$ was added dropwise to the mixture until the aqueous solution was basic. After stirring for $30 \mathrm{~min}$, the mixture was extracted three times with dichloromethane. The organic layer was washed with brine, dried over anhydrous sodium sulfate, filtered and the solvent was evaporated. The resultant solid was purified by silica gel flash chromatography using methanol/dichloromethane mixtures as eluent and recrystallized from dichloromethane/hexane mixtures to give pure compounds.

\section{Ethyl 5-amino-2-methyl-4-phenyl-1,4,6,7,8,9-}

hexahydrobenzo $[b][1,8]$ naphthyridine-3-carboxylate (3). Following the General Method for the Friedländer reaction, from compound 12 (200 mg, $0.71 \mathrm{mmol}), \mathrm{AlCl}_{3}$ (128.12 mg, $1.05 \mathrm{mmol}), \mathrm{ClCH}_{2} \mathrm{CH}_{2} \mathrm{Cl}(5 \mathrm{~mL})$, cyclohexanone (102.9 mg, $\left.1.05 \mathrm{mmol}\right)$, after $5 \mathrm{~h}$, product $3(245.5 \mathrm{mg}, 96 \%)$ was obtained: $\mathrm{mp} 213-215^{\circ} \mathrm{C}$; IR $(\mathrm{KBr}) \vee 3411$, 2932, 1664, 1634, 1448, $1242 \mathrm{~cm}^{-1} ;{ }^{1} \mathrm{H}$ NMR (DMSO-d $\left.6,300 \mathrm{MHz}\right) \delta 9.14$ (s, $1 \mathrm{H}, \mathrm{NH}$ ), $7.31\left(\mathrm{~d}, J_{2^{\prime}-3}=7.1 \mathrm{~Hz}, 2 \mathrm{H}, 2 \times \mathrm{H} 2^{\prime}\right), 7.15\left(\mathrm{dd}, J_{3^{\prime}-2}=7.1 \mathrm{~Hz}, J_{3^{\prime}-4}=7.4 \mathrm{~Hz}, 2 \mathrm{H}, 2 \mathrm{x}\right.$ H3), 7.05 (t, $\left.J_{4^{\prime}-3}=7.4 \mathrm{~Hz}, 1 \mathrm{H}, \mathrm{H} 4\right), 5.26$ (br s, $2 \mathrm{H}, \mathrm{NH}_{2}$ ), 4.99 (s, $\left.1 \mathrm{H}, \mathrm{H} 4\right), 3.95$ (q, 
$\left.J=7.1 \mathrm{~Hz}, 2 \mathrm{H}, \mathrm{OCH}_{2} \mathrm{CH}_{3}\right), 2.53-2.22$ (m, $\left.2 \mathrm{H}, \mathrm{H} 9\right), 2.30$ [s, $3 \mathrm{H}, \mathrm{CH}_{3}(\mathrm{C} 2)$ ], 2.16-2.05

(m, $2 \mathrm{H}, \mathrm{H} 6), 1.65$ (br s, $4 \mathrm{H}, \mathrm{H} 7, \mathrm{H} 8), 1.16$ (t, $\left.J=7.1 \mathrm{~Hz}, 3 \mathrm{H}, \mathrm{CH}_{3} \mathrm{CH}_{2} \mathrm{O}\right) ;{ }^{13} \mathrm{C} \mathrm{NMR}$ $\left(\mathrm{DMSO}_{6}, 75 \mathrm{MHz}\right) \delta 166.9(\mathrm{C}=\mathrm{O}), 151.9$ (C9a), 149.5 (C2), 147.8 (C10a), 147.4 (C1), 147.0 (C5), 127.6 (4C, 2C2’, 2C3), 125.7 (C4'), 110.8 (C5a), 99.7 (C4a), 98.1 (C3), $58.5\left(\mathrm{OCH}_{2} \mathrm{CH}_{3}\right), 37.8$ (C4), 31.8 (C9), 22.9* (C6), 22.4* (C7), 22.3* (C8), 19.0 $\left[\mathrm{CH}_{3}(\mathrm{C} 2)\right], 14.3\left(\mathrm{CH}_{3} \mathrm{CH}_{2} \mathrm{O}\right)$; MS (API-ES+) $\mathrm{m} / z$ : $[\mathrm{M}+1]^{+} 364.2$; [M+Na $]^{+} 386.1$; $[2 \mathrm{M}+\mathrm{Na}]^{+}$749.3. Anal. Calcd. for $\mathrm{C}_{22} \mathrm{H}_{25} \mathrm{~N}_{3} \mathrm{O}_{2}: \mathrm{C}, 72.70 ; \mathrm{H}, 6.93 ; \mathrm{N}, 11.56$. Found: $\mathrm{C}$, $72.71 ; \mathrm{H}, 6.80 ; \mathrm{N}, 11.53$.

\section{Ethyl 5-amino-4-(4-fluorophenyl)-2-methyl-1,4,6,7,8,9-}

hexahydrobenzo $[b][1,8]$ naphthyridine-3-carboxylate (4). Following the General Method for the Friedländer reaction, from compound 13 (200 mg, $0.66 \mathrm{mmol}), \mathrm{AlCl}_{3}$ (131.67 mg, $0.99 \mathrm{mmol}), \mathrm{ClCH}_{2} \mathrm{CH}_{2} \mathrm{Cl}$ (5 mL), cyclohexanone (97.02 mg, $0.99 \mathrm{mmol}$ ), after $10 \mathrm{~h}$, product 4 (240 mg, 97\%) was obtained: $\mathrm{mp} 185-187^{\circ} \mathrm{C}$; IR (KBr) v 3416, $3369,3231,2978,2933,2862,1663,1633,1603,1574,1504,1449,1382 \mathrm{~cm}^{-1} .{ }^{1} \mathrm{H}$ NMR (DMSO-d 6,300 MHz) $\delta 9.17(\mathrm{~s}, 1 \mathrm{H}, \mathrm{NH}), 7.32$ (t, J=8.5 Hz, 2 H, 2 x H2), 6.96 (t, J=8.5 Hz, 2 H, 2 x H3), 5.32 (s, 2 H, NH ), 5.01 (s, $1 \mathrm{H}, \mathrm{H} 4), 3.95$ (q, J= $7.3 \mathrm{~Hz}, 2$ $\mathrm{H}, \mathrm{OCH}_{2} \mathrm{CH}_{3}$ ), 2.52-2.48 (m, 2 H, H9), 2.27 [s, 3 H, $\mathrm{CH}_{3}(\mathrm{C} 2)$ ], 2.16-2.11 (m, $2 \mathrm{H}, \mathrm{H} 6$ ), 1.66 (br s, $4 \mathrm{H}, \mathrm{H} 7, \mathrm{H} 8$ ), 1.15 (t, $J=7.3 \mathrm{~Hz}, 3 \mathrm{H}, \mathrm{CH}_{3} \mathrm{CH}_{2} \mathrm{O}$ ); ${ }^{13} \mathrm{C}$ NMR (DMSO-d 6 , 75 MHz) $\delta 166.8(\mathrm{C}=\mathrm{O}), 162.1 / 158.8\left(J_{C^{\prime}-F}=247.5 \mathrm{~Hz}, \mathrm{C}^{\prime}\right), 152.0(\mathrm{C} 9 \mathrm{a}), 149.5(\mathrm{C} 2)$, 148.4 (C10a), 146.9 (C5), 143.6 (C1'), 129,3/129,2 ( $\left.J_{C 2^{\prime}-F}=15 \mathrm{~Hz}, \mathrm{C} 2{ }^{\prime}\right), 114,3,114,1$ $\left(J_{C 3^{\prime}-F}=15 \mathrm{~Hz}, \mathrm{C} 3\right.$ ) $, 110,8(\mathrm{C} 5 \mathrm{a}), 99,5(\mathrm{C} 4 \mathrm{a}), 98,0(\mathrm{C} 3), 58.5\left(\mathrm{OCH}_{2} \mathrm{CH}_{3}\right), 36.9(\mathrm{C} 4)$, 31.8 (C9), 22.9 (C6), 22.4* (C7), 22.2* (C8), 18.9 [ $\left.\mathrm{CH}_{3}(\mathrm{C} 2)\right], 14.2\left(\mathrm{CH}_{3} \mathrm{CH}_{2} \mathrm{O}\right)$; $\mathrm{MS}$ (API-ES+) $m / z:[\mathrm{M}+1]^{+} 382.3$; [2M+Na] $]^{+}$763.7. Anal. Calcd. for $\mathrm{C}_{22} \mathrm{H}_{24} \mathrm{FN}_{3} \mathrm{O}_{2}: \mathrm{C}$, 69.27; H, 6.34; N, 11.02. Found: C, 69.47; H, 6.49; N, 10.96.

\section{Ethyl 5-amino-2-methyl-4-(2-nitrophenyl)-1,4,6,7,8,9-}

\section{hexahydrobenzo $[b][1,8]$ naphthyridine-3-carboxylate (5). Following the General}

Method for the Friedländer reaction, from compound 14 (200 mg, $0.61 \mathrm{mmol}), \mathrm{AlCl}_{3}$ (121.7 mg, $0.915 \mathrm{mmol}$ ), $\mathrm{ClCH}_{2} \mathrm{CH}_{2} \mathrm{Cl}$ (5 mL), cyclohexanone (89.72 mg, 0.915 mmol), after $6.5 \mathrm{~h}$, product 5 (235.5 mg, 95\%) was obtained: mp 143-145 ${ }^{\circ} \mathrm{C}$; IR (KBr) $v$ 3391, 2932, 2855, 1619, 1526, $1449 \mathrm{~cm}^{-1} ;{ }^{1} \mathrm{H}$ NMR (DMSO-d $\left.6,300 \mathrm{MHz}\right) \delta 9.46$ (s, 1 $\mathrm{H}, \mathrm{NH}), 7.73\left(\mathrm{dd}, J_{6^{\prime}-4}=1.1 \mathrm{~Hz}, J_{6^{\prime}-5}=6.9 \mathrm{~Hz}, 1 \mathrm{H}, \mathrm{H} 6^{\prime}\right), 7.59\left(\mathrm{td}, J_{3^{\prime}-5}=1.1 \mathrm{~Hz}, J_{3^{\prime}-4}=\right.$ 
$\left.8.3 \mathrm{~Hz}, 1 \mathrm{H}, \mathrm{H} 3^{\prime}\right), 7.39\left(\mathrm{dd}, J_{5^{\prime}-3}=1.1 \mathrm{~Hz}, J_{5^{\prime}-6}=6.9 \mathrm{~Hz}, 1 \mathrm{H}, \mathrm{H} 5^{\prime}\right), 7.34\left(\mathrm{td}, J_{4^{\prime}-6^{\prime}}=1.1\right.$ $\mathrm{Hz}, J_{4^{\prime}-3}=8.3 \mathrm{~Hz}, 1 \mathrm{H}, \mathrm{H} 4$ ), 5.70 (br s, $2 \mathrm{H}, \mathrm{NH}_{2}$ ), 5.53 (s, $\left.1 \mathrm{H}, \mathrm{H} 4\right), 3.96$ (q, J= $7.1 \mathrm{~Hz}$, $1 \mathrm{H}, \mathrm{HA}, \mathrm{OCH}_{2} \mathrm{CH}_{3}$ ), 3.77 (qd, $\left.J=7.1 \mathrm{~Hz}, 1 \mathrm{H}, \mathrm{HB}, \mathrm{OCH}_{2} \mathrm{CH}_{3}\right), 2.57-2.48(\mathrm{~m}, 2 \mathrm{H}$, H9), 2.34-2.17 (m, 2 H, H6), 2.29 [s, 3 H, $\mathrm{CH}_{3}(\mathrm{C} 2)$ ], 1.60 (br s, 4 H, H7, H8), 1.05 (t, $\left.J=7.1 \mathrm{~Hz}, 3 \mathrm{H}, \mathrm{CH}_{3} \mathrm{CH}_{2} \mathrm{O}\right) ;{ }^{13} \mathrm{C} \mathrm{NMR}\left(\mathrm{DMSO}_{-} \mathrm{d}_{6}, 75 \mathrm{MHz}\right) \delta 166.6(\mathrm{C}=\mathrm{O}), 153.2$ (C9a), 150.51 (C2), 149.7 (C10a), 147.6 (C1) 147.5 (C5), 142.0 (C2'), 134.5 (C3'), 131.6 (C5), 127.9 (C4), 123.7 (C6), 111.4 (C5a), 98.6 (C4a), 97.6 (C3), 59.3 $\left(\mathrm{OCH}_{2} \mathrm{CH}_{3}\right), 33.9$ (C4), 32.1 (C9), 23.2* (C6), 22.7* (C7), 22.4* (C8), $19.6\left[\mathrm{CH}_{3}(\mathrm{C} 2)\right]$, $14.3\left(\mathrm{CH}_{3} \mathrm{CH}_{2} \mathrm{O}\right)$; MS (API-ES+) $m / z:[\mathrm{M}+1]^{+}$409.2; [2M+Na] ${ }^{+}$839.3. Anal. Calcd. for $\mathrm{C}_{22} \mathrm{H}_{24} \mathrm{~N}_{4} \mathrm{O}_{4}$ : C, 64.69; H, 5.92; N, 13.72. Found: C, 64.61; H, 6.04; N, 13.81.

\section{Ethyl 5-amino-2-methyl-4-(3-nitrophenyl)-1,4,6,7,8,9-}

hexahydrobenzo $[b][1,8]$ naphthyridine-3-carboxylate (6). Following the General Method for the Friedländer reaction, from compound 15 (200 mg, $0.61 \mathrm{mmol}), \mathrm{AlCl}_{3}$ (121.7 mg, $0.915 \mathrm{mmol}$ ), $\mathrm{ClCH}_{2} \mathrm{CH}_{2} \mathrm{Cl}$ (5 mL), cyclohexanone (89.7 mg, $0.915 \mathrm{mmol}$ ), after $5.2 \mathrm{~h}$, product $6(237.1 \mathrm{mg}, 95 \%)$ was obtained: $\mathrm{mp} 222-224{ }^{\circ} \mathrm{C}$; IR $(\mathrm{KBr}) \vee 3403$, 3202, 2930, 1702, 1627, 1526, 1448, 1349, $1232 \mathrm{~cm}^{-1} ;{ }^{1} \mathrm{H}$ NMR (DMSO-d $6,300 \mathrm{MHz}$ ) $\delta 9.31(\mathrm{~s}, 1 \mathrm{H}, \mathrm{NH}), 8.31\left(\mathrm{~d}, J_{2^{\prime}-6}=1.7 \mathrm{~Hz}, 1 \mathrm{H}, \mathrm{H} 2^{\prime}\right), 7.94\left(\mathrm{dd}, J_{6^{\prime}-2^{\prime}}=1.7 \mathrm{~Hz}, J_{6^{\prime}-5}=7.8\right.$ $\mathrm{Hz}, 1 \mathrm{H}, \mathrm{H6}$ ') 7.70 (d, $J_{4^{\prime}-5}=7.8 \mathrm{~Hz}, 1 \mathrm{H}, \mathrm{H} 4^{\prime}$ ), 7.47 (t, $J_{5^{\prime}-4}=J_{5^{\prime}-6^{\prime}}=7.8 \mathrm{~Hz}, 1 \mathrm{H}, \mathrm{H} 5^{\prime}$ ), 5.53 (s, $2 \mathrm{H}, \mathrm{NH}_{2}$ ), 5.21 (s, $\left.1 \mathrm{H}, \mathrm{H} 4\right), 3.95$ (q, J=7.1 Hz, $2 \mathrm{H}, \mathrm{OCH}_{2} \mathrm{CH}_{3}$ ), 2.54-2.60 (m, 2 H, H9), 2.28 [s, 3 H, $\mathrm{CH}_{3}(\mathrm{C} 2)$ ], 2.27-2.07 (m, 2 H, H6), 1.65 (br s, 4 H, H7, H8), 1.16 $\left(\mathrm{t}, J=7.1 \mathrm{~Hz}, 3 \mathrm{H}, \mathrm{CH}_{3} \mathrm{CH}_{2} \mathrm{O}\right) ;{ }^{13} \mathrm{C}$ NMR (DMSO-d 6 , $\left.75 \mathrm{MHz}\right) 166.5(\mathrm{C}=\mathrm{O}), 152.5$ (C9a), 149.7 (C2), 149.6 (C1), 149.3 (C10a), 147.2 (C5), 146.9 (C3), 134,3 (C4'), 129.2 (C5) 122.2 (C2), 120.8 (C6), 111.0 (C5a), 98.7 (C4a), 97.2 (C3), 58.7

$\left(\mathrm{OCH}_{2} \mathrm{CH}_{3}\right), 37.4(\mathrm{C} 4), 31.8(\mathrm{C} 9), 22.9^{*}(\mathrm{C} 6), 22.4^{*}(\mathrm{C} 7), 22.2^{*}(\mathrm{C} 8), 19.0\left[\mathrm{CH}_{3}(\mathrm{C} 2)\right]$, $14.1\left(\mathrm{CH}_{3} \mathrm{CH}_{2} \mathrm{O}\right)$; MS (API-ES+) $m / z:[\mathrm{M}+1]^{+} 409.2 ;[\mathrm{M}+\mathrm{Na}]^{+} 431.1 ;[2 \mathrm{M}+\mathrm{Na}]^{+}$839.3. Anal. Calcd. for $\mathrm{C}_{22} \mathrm{H}_{24} \mathrm{~N}_{4} \mathrm{O}_{4}$ : C, 64.69; H, 5.92; N, 13.72. Found: C, 64.87; H, 6.03; N, 13.55 .

\section{Ethyl 5-amino-2-methyl-4-(4-nitrophenyl)-1,4,6,7,8,9-}

hexahydrobenzo $[b][1,8]$ naphthyridine-3-carboxylate (7). Following the General Method for the Friedländer reaction, from compound 16 (200 mg, $0.61 \mathrm{mmol}), \mathrm{AlCl}_{3}$ (121.7 mg, $0.915 \mathrm{mmol}), \mathrm{ClCH}_{2} \mathrm{CH}_{2} \mathrm{Cl}$ (5 mL), cyclohexanone (89.7 mg, $0.915 \mathrm{mmol}$ ), 
after $3.5 \mathrm{~h}$, product 7 (225 mg, 94\%) was obtained: $\mathrm{mp} 201-203{ }^{\circ} \mathrm{C}$; IR $(\mathrm{KBr}) \vee 3412$, 2978, 2936, 2855, 1692, 1632, 1574, 1515, 1447, $1346 \mathrm{~cm}^{-1} ;{ }^{1} \mathrm{H}$ NMR (DMSO-d 6 , 300 MHz) $\delta 9.31$ (s, $1 \mathrm{H}, \mathrm{NH}), 8.05$ (d, J=8.8 Hz, 2 H, 2 x H3), 7.58 (d, J=8.8 Hz, 2 H, 2 x H2), 5.47 (s, $2 \mathrm{H}, \mathrm{NH}_{2}$ ), 5.20 (s, $\left.1 \mathrm{H}, \mathrm{H} 4\right), 3.95$ (q, J= 7.1 Hz, $2 \mathrm{H}, \mathrm{OCH}_{2} \mathrm{CH}_{3}$ ), 2.562.59 (m, 2 H, H9), 2.28 [s, 3 H, $\mathrm{CH}_{3}(\mathrm{C} 2)$ ], 2.12-2.07 (m, 2 H, H6), 1.67 (br s, 4 H, H7, $\mathrm{H} 8), 1.16\left(\mathrm{t}, J=7.1 \mathrm{~Hz}, 3 \mathrm{H}, \mathrm{CH}_{3} \mathrm{CH}_{2} \mathrm{O}\right) ;{ }^{13} \mathrm{C} \mathrm{NMR}$ (DMSO-d 6 , $\left.75 \mathrm{MHz}\right) 166.5(\mathrm{C}=\mathrm{O})$, 154.9 (C1), 152.5 (C9a), 149.7 (C2), 149.3 (C10a), 146.8 (C5), 145.6 (C4), 128.7 (C2), 123.2 (C3), $111.0(\mathrm{C} 5 \mathrm{a}), 98.5(\mathrm{C} 4 \mathrm{a}), 96.8(\mathrm{C} 3), 58.6\left(\mathrm{OCH}_{2} \mathrm{CH}_{3}\right), 37.7$ (C4), 31.8 (C9), 22.9 (C6), 22.3* (C7), 22.2* (C8), $19.0\left[\mathrm{CH}_{3}(\mathrm{C} 2)\right], 14.2\left(\mathrm{CH}_{3} \mathrm{CH}_{2} \mathrm{O}\right)$; $\mathrm{MS}$ (API-ES+) $m / z:[\mathrm{M}+1]^{+} 409.2 ;[2 \mathrm{M}+\mathrm{Na}]^{+}$839.5. Anal. Calcd. for $\mathrm{C}_{22} \mathrm{H}_{24} \mathrm{~N}_{4} \mathrm{O}_{4}: \mathrm{C}$, 64.69; H, 5.92; N, 13.72. Found: C, 64.65; H, 5.86; N, 13.64.

\section{Ethyl 5-amino-2-methyl-4-(4-methylphenyl)-1,4,6,7,8,9-}

\section{hexahydrobenzo $[b][1,8]$ naphthyridine-3-carboxylate $(8)$. Following the General} Method for the Friedländer reaction, from compound 17 (200 mg, $0.67 \mathrm{mmol}), \mathrm{AlCl}_{3}$ (134.22 mg, $1.01 \mathrm{mmol}), \mathrm{ClCH}_{2} \mathrm{CH}_{2} \mathrm{Cl}(5 \mathrm{~mL})$, cyclohexanone (98.97 mg, $1.01 \mathrm{mmol}$ ), after 8.5 h, product 8 (235.5 mg, 92\%) was obtained: $\mathrm{mp} 201-203^{\circ} \mathrm{C}$; IR (KBr) v 3415, 3376, 2987, 2931, 2862, 1632, $1449 \mathrm{~cm}^{-1}$; ${ }^{1} \mathrm{H}$ NMR (DMSO-d 6 , $\left.300 \mathrm{MHz}\right) \delta 9.10$ (s, 1 $\mathrm{H}, \mathrm{NH}), 7.17\left(\mathrm{~d}, J_{3^{\prime}-2}=8.0 \mathrm{~Hz}, 2 \mathrm{H}, \mathrm{H} 3^{\prime}\right), 6.95\left(\mathrm{~d}, J_{2^{\prime}-3}=8.0 \mathrm{~Hz}, 2 \mathrm{H}, \mathrm{H} 2^{\prime}\right), 5.20\left(\mathrm{~s}_{\mathrm{brs}}, 2\right.$ $\mathrm{H}, \mathrm{NH}_{2}$ ), 4.92 (s, $\left.1 \mathrm{H}, \mathrm{H} 4\right), 3.94$ (q, J= 7.1 Hz, $2 \mathrm{H}, \mathrm{OCH}_{2} \mathrm{CH}_{3}$ ), 2.54-2.31 (m, $2 \mathrm{H}, \mathrm{H} 9$ ), 2.27-2.07 (m, $2 \mathrm{H}, \mathrm{H6}), 2.25$ [s, $3 \mathrm{H}, \mathrm{CH}_{3}(\mathrm{C} 4)$ ], 2.17 [s, $3 \mathrm{H}, \mathrm{CH}_{3}(\mathrm{C} 2)$ ], 1.65 ( $\mathrm{s}_{\mathrm{brs}}, 4 \mathrm{H}$, $\mathrm{H} 7, \mathrm{H} 8), 1.16\left(\mathrm{t}, J=7.1 \mathrm{~Hz}, 3 \mathrm{H}, \mathrm{CH}_{3} \mathrm{CH}_{2} \mathrm{O}\right.$ ); ${ }^{13} \mathrm{C}$ NMR (DMSO-d 6 , $\left.75 \mathrm{MHz}\right) \delta 167.2$ (C=O), 152.2 (C1'), 149.2 (C9a), 148.4 (C2), 147.3 (C10a), 144.9 (C5), 135.0 (C4), 128.6 ( 2 x C2'), 127.9 ( 2 x C3), 111.2 (C5a), 100.2 (C4a), $98.5(\mathrm{C} 3), 58.8\left(\mathrm{OCH}_{2} \mathrm{CH}_{3}\right)$, 37.7 (C4), 32.2 (C9), 23.3 (C6), 22.8* (C7), 22.6*(C8), 22.9 [CH${ }_{3}\left(\mathrm{C}^{*}\right)$ )], 19.3 $\left[\mathrm{CH}_{3}(\mathrm{C} 2)\right], 14.6\left(\mathrm{CH}_{3} \mathrm{CH}_{2} \mathrm{O}\right)$; MS (API-ES+) $\mathrm{m} / \mathrm{z}:[\mathrm{M}+1]^{+}$378.3; [M+Na $]^{+} 400.2$; $[2 \mathrm{M}+1]^{+}$755.5. Anal. Calcd. for $\mathrm{C}_{23} \mathrm{H}_{27} \mathrm{~N}_{3} \mathrm{O}_{2}: \mathrm{C}, 73.18 ; \mathrm{H}, 7.21 ; \mathrm{N}, 11.13$. Found: $\mathrm{C}$, 73.27; H, 6.99; N, 11.40 .

\section{Ethyl 5-amino-2-methyl-4-(2-methoxyphenyl)-1,4,6,7,8,9-}

hexahydrobenzo $[b][1,8]$ naphthyridine-3-carboxylate (9). Following the General Method for the Friedländer reaction, from compound 18 (200 mg, $0.63 \mathrm{mmol}), \mathrm{AlCl}_{3}$ (127.28 mg, $0.96 \mathrm{mmol}), \mathrm{ClCH}_{2} \mathrm{CH}_{2} \mathrm{Cl}(5 \mathrm{~mL})$, cyclohexanone (93.8 mg, $0.96 \mathrm{mmol}$ ), 
after $9.5 \mathrm{~h}$, product $9(161.5 \mathrm{mg}, 64 \%)$ was obtained: $\mathrm{mp} 196-198^{\circ} \mathrm{C}$; IR $(\mathrm{KBr}) \vee 3383$, 2931, 1619, 1574, $1450 \mathrm{~cm}^{-1}$; ${ }^{1} \mathrm{H}$ NMR (DMSO-d 6 , $\left.300 \mathrm{MHz}\right) \delta 9.15$ (s, $1 \mathrm{H}, \mathrm{NH}$ ), 7.12 (m, 2 H, H3', H6'), 6.88 (m, 2 H, H4', H5'), 5.41 (br s, 2 H, NH NH $^{2}, 5.26$ (s, 1 H, H4), 3.90 [s, $3 \mathrm{H}, \mathrm{CH}_{3} \mathrm{O}\left(\mathrm{C} 2^{\prime}\right)$ ], 3.84 (q, J= 7.1 Hz, $2 \mathrm{H}, \mathrm{OCH}_{2} \mathrm{CH}_{3}$ ), 2.50-2.44 (m, $2 \mathrm{H}, \mathrm{H} 9$ ), 2.33 [s, 3 H, $\mathrm{CH}_{3}(\mathrm{C} 2)$ ], 2.23-2.17 (m, $2 \mathrm{H}, \mathrm{H} 6$ ), 1.65 (br s, 4 H, H7, H8), 1.03 (t, J= 7.1 $\left.\mathrm{Hz}, 3 \mathrm{H}, \mathrm{CH}_{3} \mathrm{CH}_{2} \mathrm{O}\right) ;{ }^{13} \mathrm{C}$ NMR (DMSO, $\left.75 \mathrm{MHz}\right) \delta 166.7(\mathrm{C}=\mathrm{O}), 153.8(\mathrm{C} 2), 151.5$ (C1), 149.8 (C9a), 148.8 (C2), 146.5 (C10a), 136.5 (C5), 129.5*(C3) $127.1 *\left(\mathrm{C}^{\prime}\right)$, 121.4* (C5), 110.4* (C6), 110.1 (C5a), 100.3 (C4a), 98.1 (C3), $58.3\left(\mathrm{OCH}_{2} \mathrm{CH}_{3}\right), 54.7$ [CH $\left.\mathrm{CH}_{3} \mathrm{O}\left(\mathrm{C} 2^{\prime}\right)\right], 31.6^{*}(\mathrm{C} 4), 30.4(\mathrm{C} 9), 22.8(\mathrm{C} 6), 22.3^{*}(\mathrm{C} 7), 22.2^{*}(\mathrm{C} 8), 19.2\left[\mathrm{CH}_{3}(\mathrm{C} 2)\right]$, $14.3\left(\mathrm{CH}_{3} \mathrm{CH}_{2} \mathrm{O}\right)$. Anal. Calcd. for $\mathrm{C}_{23} \mathrm{H}_{27} \mathrm{~N}_{3} \mathrm{O}_{3}: \mathrm{C}, 70.21 ; \mathrm{H}, 6.92 ; \mathrm{N}, 10.68$. Found: $\mathrm{C}$, $69.92 ; \mathrm{H}, 7.21 ; \mathrm{N}, 10.44$.

\section{Ethyl 5-amino-2-methyl-4-(3-methoxyphenyl)-1,4,6,7,8,9-}

hexahydrobenzo $[b][1,8]$ naphthyridine-3-carboxylate (10). Following the General Method for the Friedländer reaction, from compound 19 (200 mg, $0.63 \mathrm{mmol}), \mathrm{AlCl}_{3}$ (127.28 mg, $0.96 \mathrm{mmol}), \mathrm{ClCH}_{2} \mathrm{CH}_{2} \mathrm{Cl}(5 \mathrm{~mL})$, cyclohexanone (93.8 mg, $0.96 \mathrm{mmol}$ ), after $9.5 \mathrm{~h}$, product $10(240 \mathrm{mg}, 95 \%)$ was obtained: $\mathrm{mp} 156-158^{\circ} \mathrm{C}$; IR (KBr) v 3407 , $3365,3224,2971,2935,2826,1630,1604,1574,1488,1447,1383,1333 \mathrm{~cm}^{-1} ;{ }^{1} \mathrm{H}$ NMR (DMSO-d 6 , $300 \mathrm{MHz}) \delta 9.13(\mathrm{~s}, 1 \mathrm{H}, \mathrm{NH}), 7.06\left(\mathrm{dd}, J_{5^{\prime}-6}=7.8 \mathrm{~Hz}, J_{5^{\prime}-4}=7.8 \mathrm{~Hz}\right.$, $\left.1 \mathrm{H}, \mathrm{H} 5^{\prime}\right), 6.92\left(\mathrm{~d}, J_{6^{\prime}-2^{\prime}}=1.9 \mathrm{~Hz}, 1 \mathrm{H}, \mathrm{H} 2^{\prime}\right), 6.83\left(\mathrm{~d}, J_{4^{\prime}-5^{\prime}}=7.8 \mathrm{~Hz}, 1 \mathrm{H}, \mathrm{H} 4\right), 6.32$ (dd, $\left.J_{6^{\prime}-5}=7.8 \mathrm{~Hz}, J_{6^{\prime}-2}=1.9 \mathrm{~Hz}, 1 \mathrm{H}, \mathrm{H} 6^{\prime}\right), 5.28\left(\mathrm{~s}, 2 \mathrm{H}, \mathrm{NH}_{2}\right), 4.97(\mathrm{~s}, 1 \mathrm{H}, \mathrm{H} 4), 3.95(\mathrm{q}, J=$ $\left.7.1 \mathrm{~Hz}, 2 \mathrm{H}, \mathrm{OCH}_{2} \mathrm{CH}_{3}\right), 3.66$ (s, $\left.3 \mathrm{H}, \mathrm{OCH}_{3}\right), 2.52-2.48$ (m, $\left.2 \mathrm{H}, \mathrm{H} 9\right), 2.26$ [s, $3 \mathrm{H}$, $\mathrm{CH}_{3}(\mathrm{C} 2)$ ], 2.17-2.11 (m, $\left.2 \mathrm{H}, \mathrm{H} 6\right), 1.66$ (br s, 4 H, H7, H8), 1.17 (t, J= 7.1 Hz, $3 \mathrm{H}$, $\mathrm{CH}_{3} \mathrm{CH}_{2} \mathrm{O}$ ); ${ }^{13} \mathrm{C}$ NMR (DMSO-d 6 , $\left.75 \mathrm{MHz}\right) \delta 166.8(\mathrm{C}=\mathrm{O}), 158.6\left(\mathrm{C}^{\prime}\right), 151.9\left(\mathrm{C}^{\prime}\right)$, 149.5 (C9a), 148.9 (C2), 148.3 (C10a), 147.0 (C5), 128.7 (C5), 119.9 (C6), 114.2 (C2), 110.8 (C5a), 110.3 (C4), 99.6 (C4a), 97.9 (C3), $58.4\left(\mathrm{OCH}_{2} \mathrm{CH}_{3}\right), 54.7$ [CH $\left.\mathrm{CH}_{3} \mathrm{O}\left(\mathrm{C} 3^{\prime}\right)\right], 37.7(\mathrm{C} 4), 31.8(\mathrm{C} 9), 22.9^{*}(\mathrm{C} 6), 22.4^{*}(\mathrm{C} 7), 22.3^{*}(\mathrm{C} 8), 18.9\left[\mathrm{CH}_{3}(\mathrm{C} 2)\right]$, 14.2 $\left(\mathrm{CH}_{3} \mathrm{CH}_{2} \mathrm{O}\right)$; MS (API-ES+) $m / z:[\mathrm{M}+1]^{+} 394.2 ;[2 \mathrm{M}+\mathrm{Na}]^{+}$809.7. Anal. Calcd. for $\mathrm{C}_{23} \mathrm{H}_{27} \mathrm{~N}_{3} \mathrm{O}_{3}$ : C, 70.21; H, 6.92; N, 10.68. Found: C, 70.47; H, 6.79; N, 10.36.

\section{Ethyl 5-amino-2-methyl-4-(4-methoxyphenyl)-1,4,6,7,8,9-}

hexahydrobenzo $[b][1,8]$ naphthyridine-3-carboxylate (11). Following the General Method for the Friedländer reaction, from compound 20 (200 mg, $0.63 \mathrm{mmol}), \mathrm{AlCl}_{3}$ 
(127.28 mg, $0.96 \mathrm{mmol}), \mathrm{ClCH}_{2} \mathrm{CH}_{2} \mathrm{Cl}(5 \mathrm{~mL})$, cyclohexanone (93.8 mg, $0.96 \mathrm{mmol}$ ),

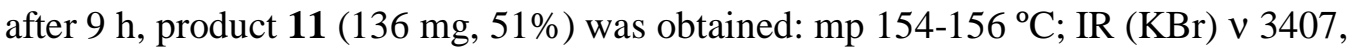
3362, 3224, 2978, 2930, 2862, 2826, 1663, 1631, 1602, 1574, 1508, 1449, $1302 \mathrm{~cm}^{-1}$; ${ }^{1} \mathrm{H}$ NMR (DMSO-d 6 , $\left.300 \mathrm{MHz}\right) \delta 9.31$ (s, $\left.1 \mathrm{H}, \mathrm{NH}\right), 7.19$ (d, J=8.3 Hz, 2 H, 2 x H3), $6.71\left(\mathrm{~d}, J=8.3 \mathrm{~Hz}, 2 \mathrm{H}, 2\right.$ x H2), 5.21 (s, $2 \mathrm{H}, \mathrm{NH}_{2}$ ), 4.92 (s, $\left.1 \mathrm{H}, \mathrm{H} 4\right), 3.94$ (q, J= 7.1 $\left.\mathrm{Hz}, 2 \mathrm{H}, \mathrm{OCH}_{2} \mathrm{CH}_{3}\right), 3.64$ (s, $\left.3 \mathrm{H}, \mathrm{OCH}_{3}\right), 2.52-2.48$ (m, $\left.2 \mathrm{H}, \mathrm{H} 9\right), 2.25$ [s, $3 \mathrm{H}$, $\mathrm{CH}_{3}(\mathrm{C} 2)$ ], 2.16-2.07 (m, 2 H, H6), 1.66 (br s, 4 H, H7, H8), 1.16 (t, J= 7.1 Hz, 3 H, $\mathrm{CH}_{3} \mathrm{CH}_{2} \mathrm{O}$ ); ${ }^{13} \mathrm{C}$ NMR (DMSO-d 6 , $\left.75 \mathrm{MHz}\right) \delta 166.9(\mathrm{C}=\mathrm{O}), 157.3\left(\mathrm{C}^{\prime}\right), 151.8$ (C9a), 149.4 (C10a), 147.8 (C2), 146.8 (C5), 139.7 (C1), 128.5 (C2), 113.0 (C3), 110.7 (C5a), 100.0 (C4a), 98.37 (C3), $58.4\left(\mathrm{OCH}_{2} \mathrm{CH}_{3}\right), 54.8$ [ $\mathrm{CH}_{3} \mathrm{O}\left(\mathrm{C}^{\prime}\right)$ )], 36.8 (C4), 31.8 (C9), 22.9 (C6), 22.4* (C7), 22.3* (C8), 18.9 [ $\left.\mathrm{CH}_{3}(\mathrm{C} 2)\right], 14.2\left(\mathrm{CH}_{3} \mathrm{CH}_{2} \mathrm{O}\right)$; MS (API$\mathrm{ES}+$ ) $m / z:[\mathrm{M}+1]^{+}$394.2; [2M+Na $]^{+}$809.5. Anal. Calcd. for $\mathrm{C}_{23} \mathrm{H}_{27} \mathrm{~N}_{3} \mathrm{O}_{3}: \mathrm{C}, 70.21 ; \mathrm{H}$, 6.92; N, 10.68. Found: C, 70.33; H, 6.89; N, 10.58.

\section{Pharmacological protocols}

Measurement of AChE activity. To assess the inhibitory activity of the compounds towards AChE, we followed the spectrophotometric method of Rappaport ${ }^{3}$ using purified AChE from-electric eel (Torpedo californica) and acetylcholine chloride $(29.5 \mathrm{mM})$ as a substrate. The reaction took place in a final volume of $2.5 \mathrm{~mL}$ of an aqueous solution containing $0.78 \mathrm{U}$ AChE and $1.9 \mathrm{mM} m$-nitrophenol to produce a yellow colour which is lost as a function of enzyme activity. Inhibition curves were made by incubating with the different compounds for $30 \mathrm{~min}$; a sample without any compound was always present to determine the $100 \%$ of enzyme activity. After the 30 min incubation, the loss of yellow colour by $m$-nitrophenol was evaluated by measuring absorbance at $405 \mathrm{~nm}$ in a spectrophometric plate reader (iEMS Reader MF, Labsystems). The concentration of compound that produces 50\% AChE activity inhibition $\left(\mathrm{IC}_{50}\right)$ was calculated by transforming the values of absorbance to Rappaport enzymatic activity units extrapolating from a calibration curve previously obtained. Data are means \pm SEM of at least three different experiments in triplicate.

Measurement of BChE activity. The inhibitory activity of the compounds towards BChE was determined following the method of Ellman ${ }^{4}$ using BChE from 
human serum and butiryl thiocholine cloride $(5 \mathrm{mM})$ as a substrate. The reaction took place in a final volume of $1 \mathrm{~mL}$ of a phosphate buffer solution at $\mathrm{pH} 7.2$ containing $0.035 \mathrm{U}$ of BChE and $0.25 \mathrm{mM} 5,5$ '-dithiobis-2-nitrobenzoic acid (DTNB) which produces the yellow anion 5-thio-2-nitrobenzoic acid. Inhibition curves were made by incubating with the different compounds for $15 \mathrm{~min}$; a sample without any compound was always present to determine the $100 \%$ of enzymatic activity. After the $15 \mathrm{~min}$ incubation period, the production of colour, as an indication of enzymatic activity, was evaluated by measuring absorbance at $412 \mathrm{~nm}$ in a spectrophotometric plate reader (iEMS Reader MF, Labsystems).

Measurement of propidium iodide displacement from the peripheral anionic site (PAS) of AChE. A solution of AChE from bovine erythrocyte at the concentration of 5 $\mu \mathrm{M}$ in $0.1 \mathrm{mM}$ Tris buffer, $\mathrm{pH} 8$ was used. Aliquots of the compounds to get the final concentrations of 0.3 and $3 \mu \mathrm{M}$ were added, and the solutions were kept at room temperature for at least $6 \mathrm{~h}$. After that time, the samples were incubated for 15 min with propidium at a final concentration of $20 \mu \mathrm{M}$ and the fluorescence was measured in a fluorescence microplate reader (FLUOstar Optima, BMG, Germany). Wavelengths of excitation and emission were 485 and $620 \mathrm{~nm}$ respectively.

Culture of SH-SY5Y cells. SH-SY5Y cells, at passages between 3 and 16 after de-freezing, were maintained in a Dulbecco's modified Eagle's medium (DMEM) containing 15 non-essential amino-acids (NEAAs) and supplemented with $10 \%$ fetal calf serum (FCS), $1 \mathrm{mM}$ glutamine, 50 units $/ \mathrm{ml}$ penicillin and $50 \mu \mathrm{g} / \mathrm{ml}$ streptomycin (reagents from GIBCO, Madrid, Spain). Cultures were seeded into flasks containing supplemented medium and maintained at $37^{\circ} \mathrm{C}$ in $5 \% \mathrm{CO}_{2} /$ humidified air. Stock cultures were passaged 1:4 twice weekly. For assays, SH-SY5Y cells were sub-cultured in 24 well plates at a seeding density of $2 \times 10^{5}$ cells per well, or in 96 well plates at a seeding density of $8 \times 10^{4}$ cells per well. For the cytotoxicity experiments cells were treated with drugs before confluence, in DMEM free of serum.

Measurement of cytosolic $\mathrm{Ca}^{2+}$ concentrations, $\left[\mathrm{Ca}^{2+}\right]$. For these experiments, SH-SY5Y neuroblastoma cells were grown at confluence in 96-well black dishes. Cells were loaded with $4 \mu \mathrm{M}$ fluo 4/AM for $1 \mathrm{~h}$ at $37^{\circ} \mathrm{C}$ in DMEM. Then cells were washed 
twice with Krebs-Hepes solution and kept at room temperature for $30 \mathrm{~min}$ before the beginning of the experiment. Fluorescence was measured in a fluorescence microplate reader (FLUOstar Optima, BMG, Germany). Wavelengths of excitation and emission were 485 and $520 \mathrm{~nm}$ respectively.

Measurement of lactic dehydrogenase (LDH) activity. Extracellular and intracellular LDH activity was spectrophotometrically measured using a Cytotoxicity Cell Death kit (Roche-Boehringer. Mannheim, Germany) according to the manufacturer's indications. Total LDH activity was defined as the sum of intracellular and extracellular LDH activity; released LDH was defined as the percentage of extracellular compared to total LDH activity.

\section{References cited}

(1) Mc Elvain, S. M. ; Tate, B. E. Further observations on the alcoholysis of diethyl diiminomalonate monohydrochloride. Some new pyrimidines. J. Am. Chem. Soc. 1951, 73, 2760-2759.

(2) Troschütz, R. Synthesis of pyrido[2,3-d]pyrimidines with a trimethoprim partial structure. Arch. Pharm. 1989, 5, 285-290.

(3) Rappaport, F.; Fischl, J.; Pinto, N. An improved method for the estimation of cholinesterase activity in serum. Clin. Chim. Acta 1959, 4, 227-230.

(4) Ellman, G. L.; Courtney, K. D.; Andres, B. J.; Featherstone, R. M. M. A new and rapid colorimetric determination of acetylcholinesterase activity. Biochem. Pharmacol. 1961, 7, 88-95. 


\section{Elemental Analyses}

\begin{tabular}{|c|c|c|c|}
\hline Comp. & Formula & \multicolumn{1}{|c|}{ Calcd. } & \multicolumn{1}{c|}{ Found } \\
\hline & & & \\
\hline $\mathbf{1 3}$ & $\mathrm{C}_{16} \mathrm{H}_{16} \mathrm{~N}_{3} \mathrm{O}_{2} \mathrm{~F}$ & $\mathrm{C}, 63.78 ; \mathrm{H}, 5.35 ; \mathrm{N}, 13.95$ & $\mathrm{C}, 63.31 ; \mathrm{H}, 5.27 ; \mathrm{N}, 13.60$ \\
\hline $\mathbf{1 4}$ & $\mathrm{C}_{16} \mathrm{H}_{16} \mathrm{~N}_{4} \mathrm{O}_{4}$ & $\mathrm{C}, 58.53 ; \mathrm{H}, 4.91 ; \mathrm{N}, 17.06$ & $\mathrm{C}, 58.76 ; \mathrm{H}, 4.91 ; \mathrm{N}, 17.12$ \\
\hline $\mathbf{1 5}$ & $\mathrm{C}_{16} \mathrm{H}_{16} \mathrm{~N}_{4} \mathrm{O}_{4}$ & $\mathrm{C}, 58.53 ; \mathrm{H}, 4.91 ; \mathrm{N}, 17.06$ & $\mathrm{C}, 58.65 ; \mathrm{H}, 4.89 ; \mathrm{N}, 17.22$. \\
\hline $\mathbf{1 6}$ & $\mathrm{C}_{16} \mathrm{H}_{16} \mathrm{~N}_{4} \mathrm{O}_{4}$ & $\mathrm{C}, 58.53 ; \mathrm{H}, 4.91 ; \mathrm{N}, 17.06$ & $\mathrm{C}, 58.35 ; \mathrm{H}, 4.87 ; \mathrm{N}, 16.86$ \\
\hline $\mathbf{1 7}$ & $\mathrm{C}_{17} \mathrm{H}_{19} \mathrm{~N}_{3} \mathrm{O}_{2}$ & $\mathrm{C}, 68.67 ; \mathrm{H}, 6.44 ; \mathrm{N}, 14.13$ & $\mathrm{C}, 68.59 ; \mathrm{H}, 6.33 ; \mathrm{N}, 14.32$ \\
\hline $\mathbf{1 8}$ & $\mathrm{C}_{17} \mathrm{H}_{19} \mathrm{~N}_{3} \mathrm{O}_{3}$ & $\mathrm{C}, 65.16 ; \mathrm{H}, 6.11 ; \mathrm{N}, 13.41$ & $\mathrm{C}, 64.93 ; \mathrm{H}, 6.40 ; \mathrm{N}, 13.61$ \\
\hline $\mathbf{1 9}$ & $\mathrm{C}_{17} \mathrm{H}_{19} \mathrm{~N}_{3} \mathrm{O}_{3}$ & $\mathrm{C}, 65.16 ; \mathrm{H}, 6.11 ; \mathrm{N}, 13.41$ & $\mathrm{C}, 65.36 ; \mathrm{H}, 6.25 ; \mathrm{N}, 13.70$ \\
\hline $\mathbf{2 0}$ & $\mathrm{C}_{17} \mathrm{H}_{19} \mathrm{~N}_{3} \mathrm{O}_{3}$ & $\mathrm{C}, 65.16 ; \mathrm{H}, 6.11 ; \mathrm{N}, 13.41$ & $\mathrm{C}, 64.89 ; \mathrm{H}, 5.97 ; \mathrm{N}, 13.09$ \\
\hline & & & \\
\hline $\mathbf{3}$ & $\mathrm{C}_{22} \mathrm{H}_{25} \mathrm{~N}_{3} \mathrm{O}_{2}$ & $\mathrm{C}, 72.70 ; \mathrm{H}, 6.93 ; \mathrm{N}, 11.56$ & $\mathrm{C}, 72.71 ; \mathrm{H}, 6.80 ; \mathrm{N}, 11.53$ \\
\hline $\mathbf{4}$ & $\mathrm{C}_{22} \mathrm{H}_{24} \mathrm{FN}_{3} \mathrm{O}_{2}$ & $\mathrm{C}, 69.27 ; \mathrm{H}, 6.34 ; \mathrm{N}, 11.02$ & $\mathrm{C}, 69.47 ; \mathrm{H}, 6.49 ; \mathrm{N}, 10.96$ \\
\hline $\mathbf{5}$ & $\mathrm{C}_{22} \mathrm{H}_{24} \mathrm{~N}_{4} \mathrm{O}_{4}$ & $\mathrm{C}, 64.69 ; \mathrm{H}, 5.92 ; \mathrm{N}, 13.72$ & $\mathrm{C}, 64.61 ; \mathrm{H}, 6.04 ; \mathrm{N}, 13.81$ \\
\hline $\mathbf{6}$ & $\mathrm{C}_{22} \mathrm{H}_{24} \mathrm{~N}_{4} \mathrm{O}_{4}$ & $\mathrm{C}, 64.69 ; \mathrm{H}, 5.92 ; \mathrm{N}, 13.72$ & $\mathrm{C}, 64.87 ; \mathrm{H}, 6.03 ; \mathrm{N}, 13.55$ \\
\hline $\mathbf{7}$ & $\mathrm{C}_{22} \mathrm{H}_{24} \mathrm{~N}_{4} \mathrm{O}_{4}$ & $\mathrm{C}, 64.69 ; \mathrm{H}, 5.92 ; \mathrm{N}, 13.72$ & $\mathrm{C}, 64.65 ; \mathrm{H}, 5.86 ; \mathrm{N}, 13.64$ \\
\hline $\mathbf{8}$ & $\mathrm{C}_{23} \mathrm{H}_{27} \mathrm{~N}_{3} \mathrm{O}_{2}$ & $\mathrm{C}, 73.18 ; \mathrm{H}, 7.21 ; \mathrm{N}, 11.13$ & $\mathrm{C}, 73.27 ; \mathrm{H}, 6.99 ; \mathrm{N}, 11.40$ \\
\hline $\mathbf{9}$ & $\mathrm{C}_{23} \mathrm{H}_{27} \mathrm{~N}_{3} \mathrm{O}_{3}$ & $\mathrm{C}, 70.21 ; \mathrm{H}, 6.92 ; \mathrm{N}, 10.68$ & $\mathrm{C}, 69.92 ; \mathrm{H}, 7.21 ; \mathrm{N}, 10.44$ \\
\hline $\mathbf{1 0}$ & $\mathrm{C}_{23} \mathrm{H}_{27} \mathrm{~N}_{3} \mathrm{O}_{3}$ & $\mathrm{C}, 70.21 ; \mathrm{H}, 6.92 ; \mathrm{N}, 10.68$ & $\mathrm{C}, 70.47 ; \mathrm{H}, 6.79 ; \mathrm{N}, 10.36$ \\
\hline $\mathbf{1 1}$ & $\mathrm{C}_{23} \mathrm{H}_{27} \mathrm{~N}_{3} \mathrm{O}_{3}$ & $\mathrm{C}, 70.21 ; \mathrm{H}, 6.92 ; \mathrm{N}, 10.68$ & $\mathrm{C}, 70.33 ; \mathrm{H}, 6.89 ; \mathrm{N}, 10.58$ \\
\hline
\end{tabular}


